\title{
TESTING FOR COMMUNITY UNITY IN THE FOSSIL RECORD
}

BENNINGTON*, J Bret, Department of Geology, 114 Hofstra University, Hempstead, NY 11550, U. S. A.; DALEY, G.M., Department of Geological Sciences, Virginia Polytechnic Institute and State University, Blacksburg, VA 24061, U. S. A.

Community unity in the fossil record, manifested by the recurrence of the same fossil assemblage through time or across space, has recently become of great interest to paleontologists. Unfortunately, testing for the presence of recurrence in the fossil record such that a statistically constrained estimate of the degree of similarity between two paleocommunities is obtained is not a trivial exercise. Complications arise from two principle sources - 1) the difficulty in quantitatively defining a paleocommunity so that the similarity between two fossil assemblages can be judged and 2) the problems involved in trying to adequately sample a paleocommunity to make meaningful quantitative comparisons possible.

Measures of the composition of a fossil assemblage can be based either on species membership (presence / absence measures) or on species abundances (abundance distribution or quantitative measures). However, a test for recurrence in two fossil assemblages cannot be based on the simple criterion of identity between their individual species compositions or species abundance distributions, because sampling will always imperfectly describe the composition of the paleocommunity. Sampling problems arise both from the presence of variability in the distribution of fossils within the paleocommunity being sampled and statistical sampling error. Variability within the bounds of a particular paleocommunity may be due to local patchiness in the distribution of organisms within the original living community, patchiness in the distribution of fossils caused by taphonomic processes, or habitat gradients that existed within the depositional environment but are not recorded in the rock.

When approaching a stratigraphic unit with the intent to describe its paleoecological composition, one must never assume that the fossils contained therein are evenly distributed within a single, time-averaged, homogeneous paleocommunity. Heterogeneity at many scales should be considered to be the rule, not the exception. Studies conducted by the authors and others in both Paleozoic and Cenozoic marine strata show that apparently continuous and homogeneous fossiliferous units are patchy at a variety of scales and more often than not can be shown to record geographic and paleoenvironmental gradients in their species compositions. The only way to determine the presence and magnitude of this variability is to design a sampling program that incorporates replicate sampling at a variety of spatial scales. For example, a trio of replicate samples taken from the same location and stratigraphic horizon at an outcrop will show the magnitude of variability expected from sampling error. Replicate samples taken from the same horizon but at three different locations at an outcrop will show variability due to small-scale patchiness and taphonómy. Replicate samples from the same stratigraphic horizon at different localities will show the presence of larger scale habitat gradients. Although labor intensive, such a sampling program allows the investigator to define the spatial scale over which a single paleocommunity occurs and to assess the amount of variability expected from samples taken within the paleocommunity. This establishes the basis for meaningful tests of paleocommunity recurrence. 